\title{
Development and applications of community-based decision support system for land use allocation at Mae Sa Mai Royal Project Development Center, Chiang Mai Province, Thailand
}

\author{
P. Witthawatchutikul $^{a}$, S. Pratummintra ${ }^{b}$, K. Ngamsomsuke ${ }^{c}$, T. Kaewumput ${ }^{a}$, \\ B. Deesaeng ${ }^{a}$, B. Chatveera ${ }^{d}$ and S. Rojanasoonthon ${ }^{d}$ \\ ${ }^{a}$ Department of National Parks, Wildlife and Plant Conservation, Ministry of Natural Resources and \\ Environment, \\ ${ }^{b}$ Department of Agriculture, Ministry of Agriculture and Cooperatives, \\ ${ }^{c}$ Department of Agricultural Economics, Faculty of Agriculture, Chiang Mai University, \\ ${ }^{d}$ Research Section, Royal Project Foundation \\ Email: dr_pongsak919@yahoo.com
}

\begin{abstract}
The Royal Project Foundation has successfully developed a computer program on decision support system for land use allocation in the watershed areas (DSSLAW). The core features of this program are the integration of the crop, hydrological, soil erosion and socio-economic models into a single model and the provision of necessary information for decision-making aimed at sustainable land use in the watershed areas. This developed decision support system was applied to a watershed area in Mae Sa Mai Royal Project Development Center by mean of role-playing game (RPG). This paper provides details on development of the program, its applications and some empirical results from the fieldwork.
\end{abstract}

Keywords: Decision Support System for Land Use Allocation at Head Water Area (DSSLAW), Role Playing Game (RPG), Community Based Research, Crop Model, Socio-economic Model, Hydrological Model, Soil Erosion Model 


\section{INTRODUCTION}

The Royal Project Foundation has been developing a program on decision support system (DSS) for planning of land use on watersheds since 1997. It first attempt was on the conduction of the Integrated Water Resources Assessment and Management Project (IWRAM) (Jakeman et al., 2005). This project focuses on stopping the farmers' invasion into the watershed areas and promoting sustainable land use in order to improve quality of life of the people in upstream communities. After about 12 years of continuously working on this project, the Royal project has successfully developed the computer program on DSSLAW. A combination of geographic information system (GIS) and mathematical model was used as a tool for the application development. The program predicts the income arising from land use decision. Moreover, it presents the overall effects of changing land use from forest areas into agricultural land on the watershed areas.

However, the applications of decision support system for land use allocation in the watershed areas (DSSLAW) only could not convince farmers to make proper land use allocation. The farmers themselves have to learn and observe from actual situations. Especially, they should perceive benefits from forest surrounding their communities. At the same time, they must experience the consequences arising from their agricultural practices as well as realize and ready to protect the watersheds. These lessons from fieldwork could stimulate farmers to restore the degraded watershed and changing patterns of their cultivation towards sustainable land use in the watershed areas.

\section{RESEARCH METHODOLOGY}

The community based research on the application of the decision support system to determine land use in the watershed consists of two parts. The first part deals with the development of the decision support system. While the second part focuses on exploring the hydrology of the watershed and the effects arising from converting the watershed into agricultural areas in Mae Sa Royal Project Development Center since 2008 using community/farmer participation approach.

The decision support system for land use on the watershed areas (DSSLAW) has of three components. The first component is the preparation of databases needed for model computation. The second one deals with the computational procedures for crop yield (Crop Model), cost and benefits from crop production (Socioeconomic Model) and the effects arising from the land use pattern such as changes in the flow of runoff into streams (Hydrological Model) and soil loss and deposit due to soil erosion (Soil Erosion Model). Finally, the third component is the display of outputs. It is not only crop yield that is displayed on the map but also economic returns and the impacts of changing land use patterns are included. The output displays also include the overall suitability of land use on the watershed areas. In addition to the display of outputs, the program provides a window for user to change input data for scenario analysis.

In order to stimulate farmers to actively participate in the use of decision support system and quickly adopt the concept of sustainable land use, they must be well prepared. The researchers ask them to discuss the significant of watershed and impacts arising from converting forest areas into agricultural land. The process is repeated for several times until the farmers express their acceptance to the concept, changing the attitudes and ready to participate in the land use planning activity.

Farmers were part of the research team. The researchers collaborated with farmers in data collection and observation of the characteristics of the watershed hydrology, amount of rainfall, interception, infiltration, surface runoff, soil erosion, and amount and flow of runoff in the streams. These data collected from the joint effort between researchers and farmers was used to validate and adjust the 4 computational procedures or models. Moreover, the experiences learned from field observations were used to raise awareness to other people in the village and neighboring areas. Figure 1 shows steps and processes of the study. 


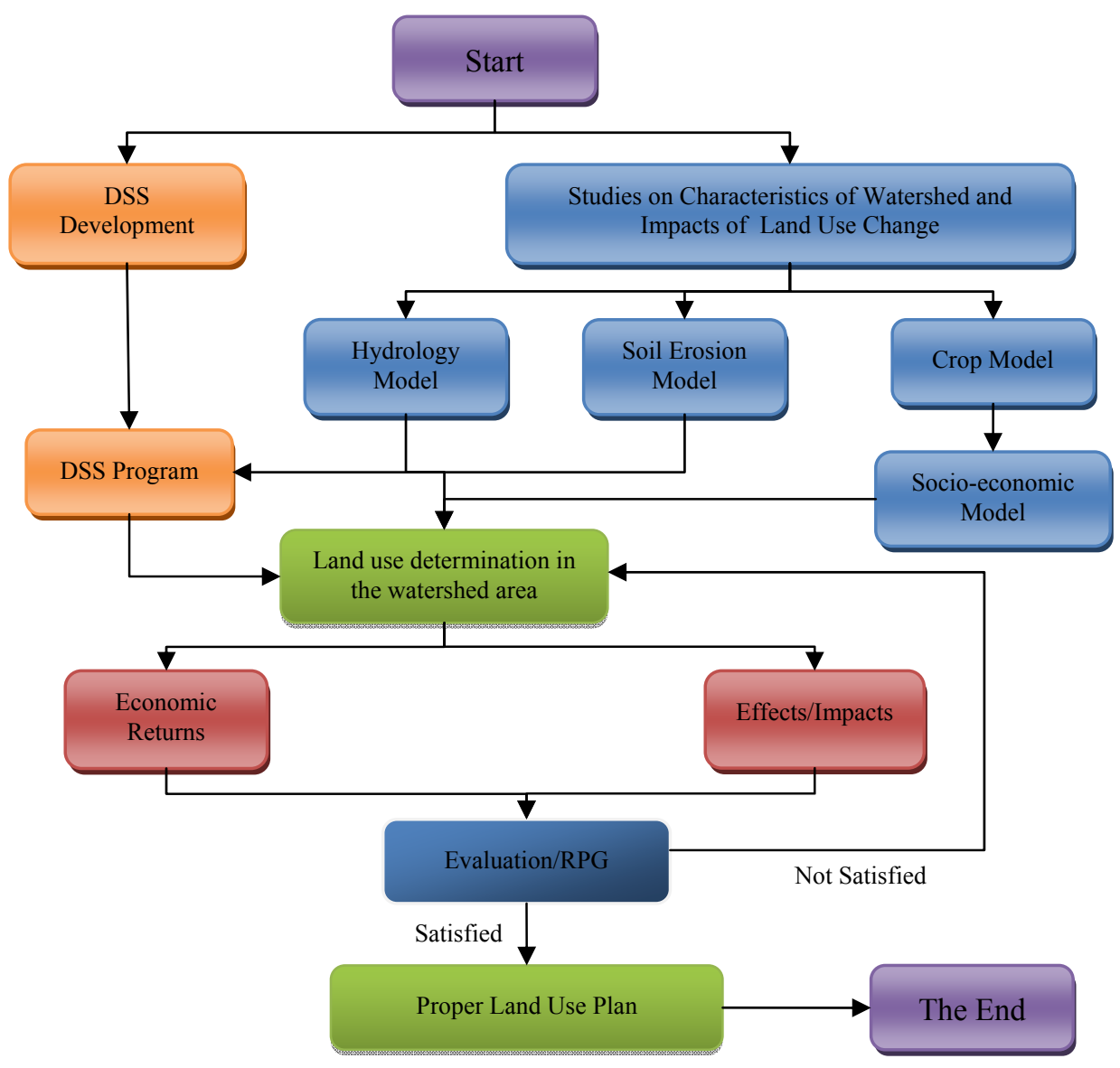

Figure 1. Processes in conducting the community based research on the application of the decision support program in this study

\section{RESULTS AND DISCUSSION}

\subsection{Development of the Decision Support Program}

The development of decision support system comprises of four main models: (1) crop model, (2) economic and social model, (3) soil erosion model, and (4) hydrological model. The first two models predict the selected crop yield and economic return on different location in the watershed. The last two models simulate soil erosion, water absorption, runoff and amount of water flow in the stream. This decision support system enables upstream and downstream farmers/stakeholders to realize not only the gain in terms of crop yield but also economic returns to crop production and the effects on the environment arising from decision on land use made by farmers on the upstream areas. Changes in land use patterns will produce different outcomes. The proper land use pattern in the watershed can be accomplished by the joint decision among upstream and downstream farmers as well as other stakeholders.

In details, the crop model evaluates the level of crop production under actual conditions in the watershed. It composes of four sub-models. The first sub-model deals with suitable planting date determination for selected crop, by using data on crop water requirement and amount of rainfall as basis for determining a starting of planting date. The second sub-model simulates the gross biomass production using data those necessary for plant photosynthesis i.e. crop growth cycle, leaf area index, soil characteristics and climate. The third sub-model is the water balance model. This sub-model predicts actual crop yield under the constraints of water available capacity in the soil resulted from rainfall. Lastly, the forth sub-model adjusts crop yield computed in the third sub-model to fit the different farm management practices such as level of fertilizer application in particular (Pratummintra, 2001).

The socio-economic model adopts crop yield resulted from the crop model together with its database on crop production cost to simulate the economic returns to crop production. Besides, the role-playing game (RPG) is used in order to apply the decision support system. The idea of role-playing game adopted in this study is to stimulate upstream and downstream farmers as well as other stakeholders jointly decide on the type of crop to grow under their socio-economic and environmental conditions (Promburom, 2010). 
The soil erosion model is a model that used to compare the level of soil loss and deposition arising from the different land use patterns according to farmer's decision. The model applied in this program was USPED (Unit Stream Power Erosion and Deposition Model) (Mitasova et. al., 1996, Mitas and Mitasova, 1998) using GIS. Data used in the model includes rainfall (R-factor), soil erodibility (K-factor), slope (LS-factor), type of crop grown and type of forest (C-factor), and soil and water conservation practices (P-factor). The required coefficients in the model were derived from standard USPED model suggested by Mitasova et. al. (1996) and Mitas and Mitasova (1998). There was the calibration of the coefficients before adopting into the DSSLAW in order to increase accuracy of the model simulation. The calibration process used data on soil loss measured at erosion plots of various land uses in Mae Sa Mai Royal Project Development Center in 2009.

The hydrological model computes the quantity and flow of water in the streams at different land use patterns. The model applied the SCS-CN Methodology. It consists of the development and test on daily runoff computed from the runoff model using coefficients derived from collected data in the forested watershed areas. After that, the data on hydrological characteristics of the natural forest and agricultural land was used to adjust the coefficients of forested watershed area to be the coefficients of crop grown in the agricultural land. The model finally simulates the daily runoff of agricultural land. The proportion of daily runoff in rainy season and annual flow is defined as criteria of hydrological model.

The daily runoff model requires three data sets. The first data set is the factors affecting the flow of water in the streams or the curve number $(\mathrm{CN})$. These factors are the characteristics of study area, infiltration, land cover and quantity and nature of the puddles. The second data set is the quantity and distribution of rainfall in previous years, which will be applied to modify the $\mathrm{CN}$ to be the Antecedent Precipitation Index (API). Finally, the third set of data required in the daily runoff model is the daily rainfall.

The original coefficients used in the daily flow model adopt those representing the hydrological characteristics of the natural forest. In order to compute for the water flow on different agricultural land, those coefficients were adjusted. The adjusting process of these coefficients requires data on interception, infiltration, permeability and amount of soil water.

\subsection{Applications of the DSSLAW}

The DSSLAW has been designed to manipulate a single plot or multiple plots. To apply the program, the user therefore must select a particular or multiple plots for manipulation and assigns a crop to be grown in each plot. The program will find necessary data from its databases and then calculates crop yield (by crop model), gross margin and net profit (by socio-economic model), soil erosion (by erosion model) and change in quantity and flow of runoff in the streams. At the same time, the program computes suitability indices of each model on each selected plot as well as overall suitability index (see Figure 2). There are three suitability levels namely, suitable, suitable with conditions and unsuitable.

As will be performed by role-playing game (RPG), the meeting among farmers in upstream and downstream communities as well as other stakeholders can be arranged. They can discuss to change types of crop that will be grown at upstream areas. Obviously, the selected crops do not only produce income for farmers at upstream communities but also influence sustainability to downstream communities. Each stakeholder will protect himself/herself during crop selection. Upon agreement among farmers and stakeholders participating in the meeting, these new selected crops are put into the program for the computation. The calculated outputs are presented in terms of the comparison between old and new land use scenarios. These results show the different outputs in each plot. Moreover, the perspective before and after changing crops and the overall status of cropping areas at upstream are presented. Figure 3 presents program's outputs for a single plot. 
Witthawatchutikul et al., Development and applications of a community-based decision...

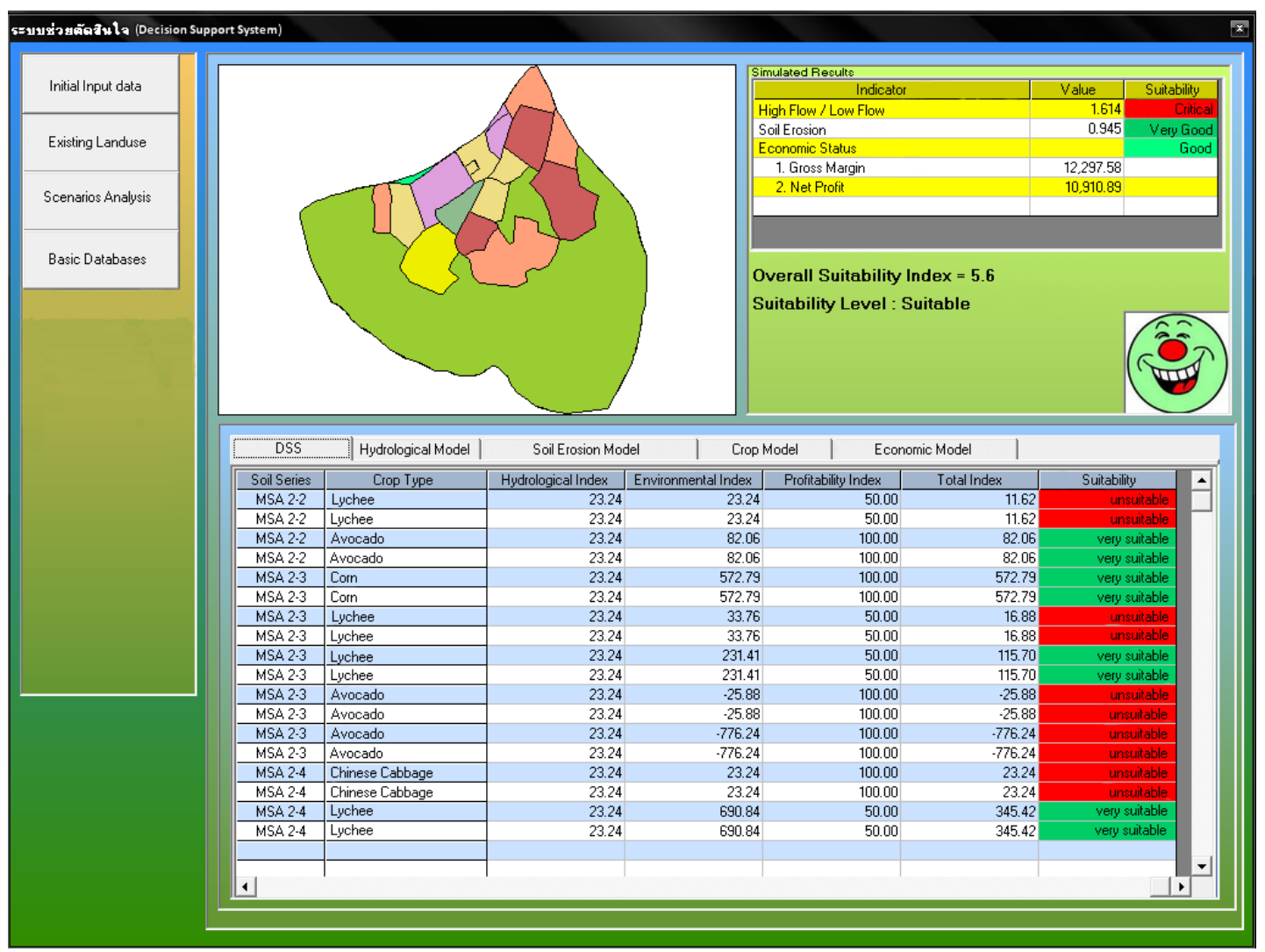

Figure 2. Display of the type of land use on map and the computed indicators for decision-making

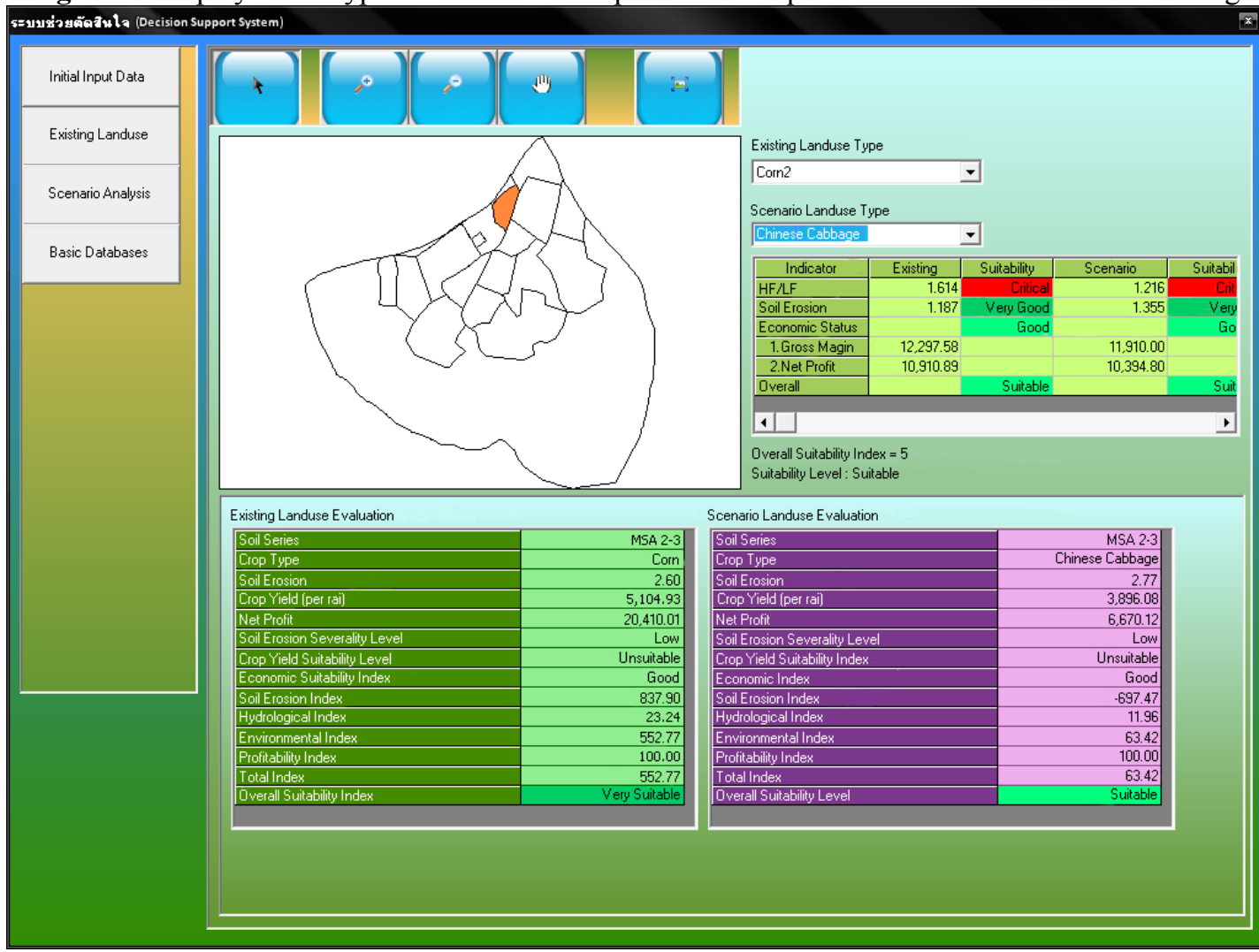

Figure 3. The results of the changing land use display on map and indicators for decision-making 


\subsection{Results from the Fieldwork}

The field observation and data collection was conducted during June 2008 to August 2010 by the participation of volunteer farmers and young scientists. The results of field observation enabled people to perceive changes of forest areas (which able to protect $12 \mathrm{~mm}$ maximum of rainfall) to agricultural areas (which able to protect $8 \mathrm{~mm}$ maximum of rainfall). Such changes caused ground getting more direct impact from rainfall. Deforestation and crop cultivation in the watershed area caused the $33.66 \%$ and $23.87 \%$ decline in infiltration and permeability, respectively. There was 2.6 times increase in the rate of declining in permeability to its constant rate $(\mathrm{k})$.

The reduction of infiltration and permeability at upstream area after converting forest area into corn, vegetables and lychee plantation caused the surface runoff increases by $2.71,3.17$ and 2.80 times, respectively. Moreover, the surface runoff still increases the soil erosion and removes eroded soil out of the areas by 98.04 , 73.23 and 31.49 times, respectively.

On the hydrological model, it is obvious that if soil infiltration level is low, the amount and flow of runoff will increase. The hydrological simulation results showed that there were higher amount of runoff and the flow increased by 2.90 times arising from converting forest area into agricultural land.

Thought the DSSLAW program has been successfully developed, it needs additional development and refinement in order to increase its predictive accuracy and calculating efficiency. Therefore, the present study applied only the process of preparing farmers and stakeholders for the role-playing game. The research project identified three groups of the stakeholders. They were upstream farmers, downstream farmers and government officers from various agencies such as Department of Land Development, Royal Forestry Department, Royal Project Foundation.

A another decision support system for land use determination in the watershed area was formulated at Dong Nai Watershed in Vietnam (Kim Loi, 2006). This DSS used in the linear/goal programming model to find optimal land use pattern given socio-economic, physical and environmental requirements. Three scenarios were analyzed, i.e. present watershed scenario, maximizing economic scenario and maximizing environmental scenarios. The optimal land use pattern was then distributed onto geographical areas using spatial planning algorithm in ArcView GIS software. The spatial planning algorithm adopted conflict management and varieties of geographical criterions such as slope, soil depth and rainfall. Though the DSS developed by Kim Loi could provide land use pattern on map, it did not provide sufficient information on coefficients used in the optimization of land use. If these coefficients were not reflect the biophysical properties of land and crop grown, the distribution of optimal solution onto the geographical area may not actually produce the same levels of income, water discharge and sediment yield as they were used in the model. At the same time, it did not provide any indicator for decision-making. Our DSSLAW did not have this problem. Even though our DSSLAW did not provide optimal land use pattern it has the advantages on being integrated compact software, ability to change land use with interactive simulated results and provision of several indicators for decision-making.

The process of conducting role-playing game (RPG) is gradually developed. Firstly, the farmers were familiarized with the researchers and the project. They were informed about the project goal, objectives, activities and their expected roles (Figure 4). The farmers could make their reactions, comments and suggestions to the project. The researchers had responded to the famers' requests whatever the project could serve. The project arranged several meetings and asked them to express their opinions on crop choices which supposed they were themselves or other stakeholders. The farmers also took part in data collection and field observation as mentioned above. Lastly, the farmers were familiarized with the decision support system and its output (Figure 4).

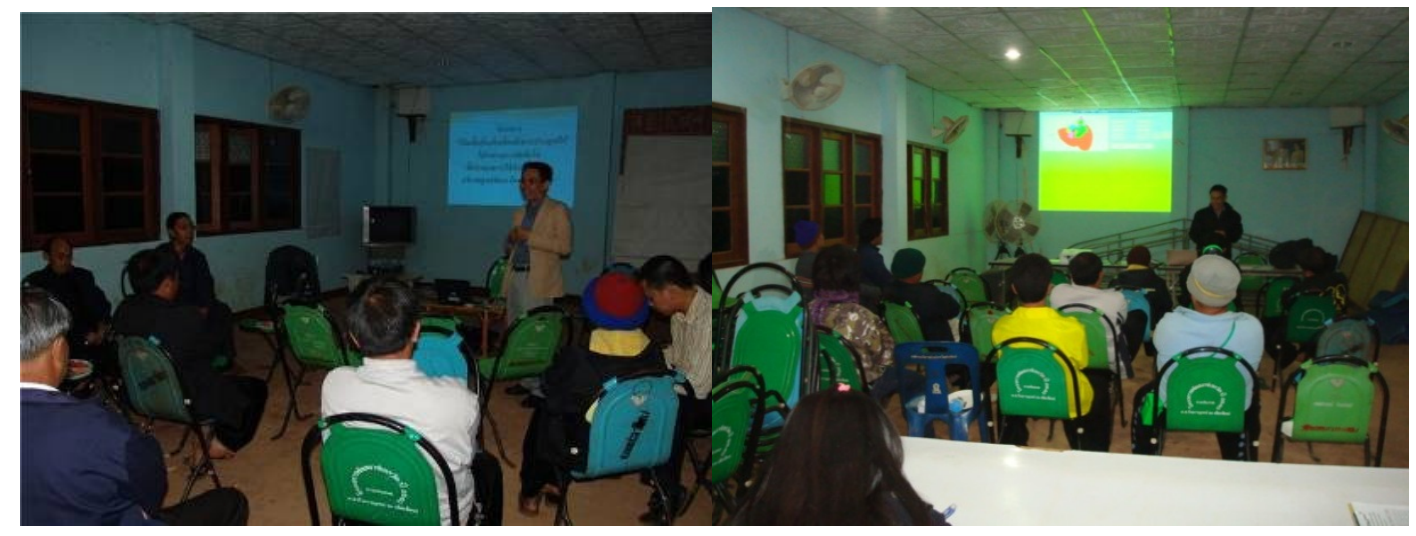

Figure 4. To prepare the public to participate in decision-making process for land use planning on a watershed 


\section{CONCLUSIONS}

The Royal Project Foundation has successfully developed the decision support system for land use allocation in the watershed areas (DSSLAW). This DSSLAW program has been developed to the point where the four models (i.e. crop, hydrological, soil erosion and socio-economic models) were well integrated into a single computerized program. This program needs some further development. There are some functions and coefficients needed to be corrected, adjusted and refined. The program produces necessary and useful information for sustainable land use planning/decision-making in a watershed of Mae Sa Mai Royal Project Development Center.

In case of the stakeholder preparation for role-playing game and participatory approach to the project implementation, some farmers have been self-learning. They observed that the conversion of forest areas into agricultural areas caused higher direct impact of rainfall to the ground. The reduction of infiltration rate could cause flash flooding, soil erosion, increase the volume of surface runoff and strong water flow in the streams. At present, the farmers are ready to attend the land use planning on their watershed using role-playing game.

\section{REFERENCES}

Jakeman, A.J., R.A. Letcher, S. Rojanasoonthon and S. Cuddy ed. 2005. Integrating knowledge for river basin management, Progress in Thailand. ACIAR Monograph No. 118, 220p.

Mitas, L., and H. Mitasova. 1998. Distributed soil erosion simulation for effective erosion prevention. Water Resources Research, 34(3): 505-516.

Mitasova, H., J. Hofierka, M. Zlocha, and R. L. Iverson. 1996. Modeling topographic potential for erosion and deposition using GIS. International Journal of GIS, 10(5): 629-641.

Nguyen Kim Loi. 2006. Decision Support System (DSS) and GIS for sustainable watershed management in Dong Nai watershed, Vietnam . Paper presented in International Symposium on GeoInformatics for Spatial-Infrastructure Development in Earth and Allied Sciences,November 9-11, 2006 , Rex Hotel, Ho Chi Minh City, Vietnam.

Pratummintra, S. 2001. Development of Decision Support System for Determining Crop Management Plan: A case study of rubber and palm oil. Department of Agriculture, $213 \mathrm{pp}$.

Promburom, P. 2010. Participatory Modeling for Watershed Management: The Use Role-playing Game and MAS Model. [Online Available] http://www.uni-koblemz.de/ essa/ESSA2004/files/papers/promburom_ESSA04.pdf 